\title{
Avaliação da liberação da rutina associada ao ultrassom contínuo
}

\author{
Rutin release assessment associated with continuous ultrasound
}

Francielli Valandro, João Alberto Fioravante Tassinary, Paula Bianchetti, Barbara Schmitt, Laís Bresciani, Simone Stülp

Centro Universitário Univates, Lajeado, RS, Brasil.

\section{Resumo}

A pele intacta pode ser usada como uma porta de administração sistêmica. Profissionais da saúde vêm associando princípios ativos ao recurso ultrassônico, técnica denominada fonoforese. Um princípio ativo comumente utilizado na prática clínica é a rutina. A rutina classifica-se como um flavonóide da classe dos flavonóis, é também utilizada como antioxidante, na prevenção ou tratamento da deficiência venosa ou linfática e da fragilidade ou permeabilidade capilar. O objetivo deste estudo foi investigar a liberação de gel contendo rutina $5 \%$ frente à aplicação de fonoforese (US contínuo) in vitro para que, possa ser avaliada a eficácia do seu emprego terapêutico. Foram preparadas amostras contendo rutina $5 \%$ em meio hidrogel, as amostras foram analisadas com e sem a aplicação da fonoforese nos tempos de 5, 10, 15 e 20 minutos. Os resultados mostram que não existe diferença em termos de difusão em 5 e 10 minutos, porém nos tempos 15 e 20 minutos se pode evidenciar um incremento significativo do princípio ativo para o meio receptor quando aplicada a fonoforese. O US contínuo se apresentou como facilitador no processo de liberação da rutina para o meio, sendo que este fato está relacionado ao tempo de irradiação sonora.

Palavras-chave: Fisioterapia, ultrassom, rutina.

\begin{abstract}
The intact skin can be used as a gate of systemic administration. The health professionals have been associating active principles of the ultrasonic feature, technique called phonophoresis. An active principle commonly utilized in the clinical practice is the rutin. The rutin is classified as a flavonoid from the flavonols class, it's also used as an antioxidant in the prevention or treatment of venous or lymphatic deficiency and the fragility or capillary permeability. The aim was investigate the release of Rutin, 5\% through the use of phonophoresis in vitro so it can be assessed the effectiveness of its therapeutic use. Samples were prepared containing rutin 5\% half gel, the samples were analyzed with and without the application of phonophoresis at times of 5, 10, 15, and 20 minutes. The results show that there isn't difference in permeation at 5 and 10 minutes, however at times 15 and 20 minutes we can evidence a meaningful increase of the active principle to the receiver environment when applied the technique of phonophoresis. The continuous US was presented as a facilitator in the release process of rutin to the environment, this fact is related to the time of sound irradiation.
\end{abstract}

Keywords: Physiotherapy. ultrasound. rutin. 


\section{Introdução}

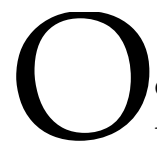

sistema tegumentar é o maior órgão do corpo humano, composto pela epiderme e também por um tecido conectivo composto de derme reticular e papilar (Harris, 2003). A Epiderme é um tecido queratinizado e pavimentoso, constituído por cinco camadas, sendo a primeira delas o estrato córneo, seguida pelas camadas, granulosa, espinhosa e germinativa (Guirro; Guirro, 2002). Historicamente a pele é um órgão de proteção do corpo humano que, dentre as inúmeras funções, tem a finalidade de inibir a migração de agentes externos que possam a vir a prejudicar o organismo (Guirro; Guirro, 2002).

$\mathrm{Na}$ atualidade, reconhece-se que o sistema tegumentar intacto pode ser usado como uma porta de administração sistêmica ou local de drogas (Banga, 2011). A administração transdérmica de fármacos oferece muitas vantagens sobre outras vias de administração com potencial eficácia superior e efeitos colaterais mínimos, para uma variedade de condições médicas e de doenças (Carter et al., 2013). Sob diversas circunstâncias, as vantagens culminam na efetividade de tratamento com facilidade de aplicação, competente entrega do princípio ativo e consequente conforto ao seguimento de tratamento pelos pacientes (Carter et al., 2013).

Na prática clínica, inúmeros são o recursos eletrotermofototerápicos usados como ferramentas, na realidade dos mais diferentes tipos de lesões de cura nos tecidos moles e aliviar a dor (Guirro; Guirro, 2002) (Prentice, 2004). Um desses recursos é o ultrassom, que caracteriza-se como peça fundamental no tratamento dos distúrbios músculo-esqueléticos (Kitchen; Bazin, 1998). O ultrassom tem efeito benéfico de reparação tecidual, este tem sido demonstrado sobre diversos tecidos, incluindo a pele. $\mathrm{O}$ aparelho aumenta a angiogênese do tecido de granulação, o número de fibroblastos, síntese de colágeno, etc (Young; Dyson, 1990).

Com a finalidade de potencializar os efeitos supracitados, os profissionais da saúde vêm associando princípios ativos de diferentes finalidades ao recurso ultrassônico, esta técnica é denominada fonoforese. É essencial destacar que a promoção de permeação de fármacos pela pele através da onda sônica pode levar a uma maior liberação de ativos; aumentando o fluxo ou retenção do mesmo, como também promovendo o aumento da liberação localizada nos tecidos aplicados (Rogero et al., 2003).

Um princípio ativo comumente utilizado na prática clínica e que recentemente vem sendo estudado in vitro é a rutina. A rutina classifica-se como um flavonoide da classe dos flavonóis, é também utilizada como antioxidante, na prevenção ou tratamento da deficiência venosa ou linfática e da fragilidade ou permeabilidade capilar (Bruneton, 1991), (Velasco et al., 2008).

Dentro deste contexto, o objetivo deste estudo foi investigar a liberação do gel contendo rutina $5 \%$ frente à aplicação de fonoforese in vitro, com aplicação de US contínuo, para que assim, possamos compreender em termos quantitativos a real eficácia do seu emprego terapêutico.

\section{Material e Método}

\subsection{Reagentes e preparo das amostras}

As amostras utilizadas na análise foram obtidas a partir de gel condutor da marca RMC (ácido carboxivinílico/Carbopol), registrado na ANVISA sob número 80122200001, lote: 162601, data de fabricação: 10/01/2013, com adição de rutina a 5\%, produzido pelo laboratório SigmaAldrich, 94\% (HPLC), referência: R3143-50G, lote: BCBL7548, data de fabricação: 04/12/2013 e data de validade: 23/01/2019. Esta concentração de rutina foi utilizada por ser a comumente encontrada em géis comerciais para aplicações fisioterapêuticas. Para garantir a homogeneidade da amostra utilizou-se um agitador mecânico da marca Fisatom modelo 703 D.

Nos ensaios de liberação utilizou-se um sistema de difusão vertical com membrana de acetato de celulose.

\subsection{Aplicação do ultrassom terapêutico} in vitro

$\mathrm{O}$ equipamento de ultrassom utilizado no experimento foi da marca Tonederm, com cabeçote de $1 \mathrm{MHz}$, fornecido pelo laboratório de 
Eletrofotoquímica da Univates. O parâmetro utilizado foi o modo contínuo com dose de 1,0 $\mathrm{W} / \mathrm{cm}^{2}$.

\subsection{Análise de liberação da rutina em sistema de difusão vertical}

As amostras foram analisadas com e sem a aplicação da fonoforese nos tempos de 0, 5, 10, 15 e 20 minutos. As análises de liberação da rutina foram realizadas em uma célula de difusão vertical tipo Franz, com solução receptora de água deionizada e álcool etílico $99,5 \%$ com proporção de 1:1, contendo uma membrana de acetato de celulose (Sartorius Stedim Biotech com porosidade de $0,45 \mu \mathrm{m}$ e área de $7,06 \mathrm{~cm}^{2}$ ) com a finalidade de separar o compartimento doador do receptor, formando uma barreira não interferente a um fluido denominado receptor (Mota et al., 2008). A célula de difusão foi introduzida em banho termostatizado (MARCONI) à $37^{\circ} \mathrm{C}$, simulando a temperatura corporal. Em contato com a membrana foi adicionado o agente acoplador, rutina em gel.

Com a finalidade de determinar a concentração de rutina permeada nas amostras analisadas a partir dos valores de absorbância obtidos em $272 \mathrm{~nm}$, foi realizada uma curva de calibração a partir de soluções de rutina em água e álcool etílico 1:1, com diferentes concentrações. O intervalo de concentrações estudado foi de: 0,03 a $5 \mathrm{mg} \cdot \mathrm{L}^{-1}$. A partir disso obteve-se a equação da reta, sendo que a curva obtida foi: $y=$ 0,0091 . $x-0,12906$, com $R=0,9964$.

Todas as análises foram realizadas em triplicatas, os resultados expressos em média e erro padrão da média (EPM). Foi utilizado o teste de Shapiro-Wilk para averiguar normalidade dos dados. Os parâmetros com dois grupos, foi utilizado o teste de $\mathrm{t}$ de Student. Em todos os casos, os resultados foram considerados estatisticamente significativos quando $\mathrm{p}<0,05$. Todas as análises foram realizadas utilizando o software SPSS (Statistical Package for the Social Sciences) versão 18.0.

\section{Resultados e Discussões}

\subsection{Análise da liberação da rutina}

Através de varredura na faixa espectral (190900nm) foram considerados os valores próximos a $272 \mathrm{~nm}$ como a região de absorbância máxima. Na Figura 1 tem-se a calibração da rutina no intervalo de concentrações de 0,03 a 5 mg. $\mathrm{L}^{-1}$.

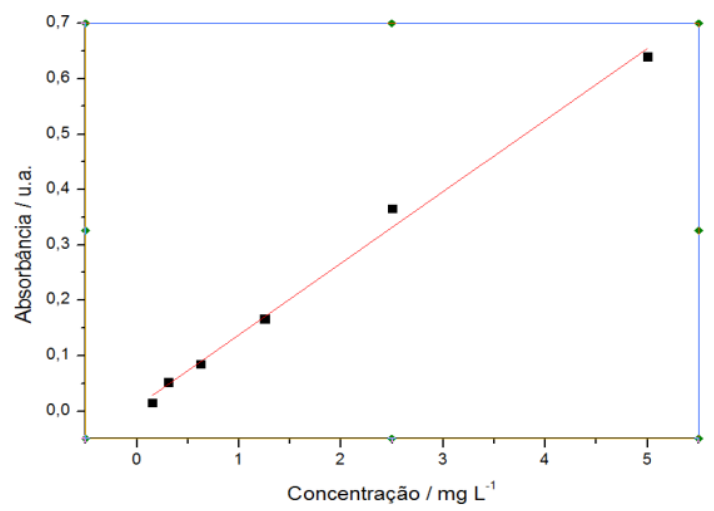

Figura 1: Curva de calibração da rutina para determinação da concentração liberada. Fonte: Dos autores (2014).

A partir da curva apresentada na Figura 1, pode-se comparar a liberação de rutina 5\% para o meio receptor com e sem a aplicação de fonoforese nos tempos 5, 10, 15 e 20 minutos, conforme Figura 2.

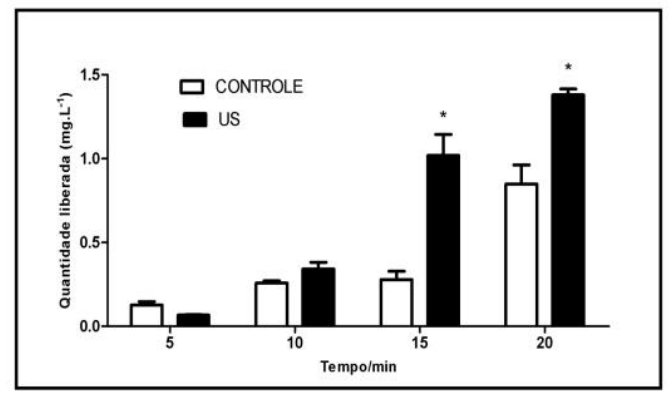

Figura 2: Gráfico comparativo da liberação da rutina através da membrana de acetato de celulose, com e sem a aplicação do ultrassom terapêutico nos tempos de 5, 10, 15 e 20 minutos. Fonte: Dos autores (2014).

Os resultados do gráfico (FIGURA 2) mostram que não existe diferença em termos de liberação da rutina em 5 e 10 minutos, em sistemas com e sem aplicação da onda acústica. No entanto, nos tempos 15 e 20 minutos pode-se evidenciar um incremento significativo do princípio ativo para o meio receptor quando aplicada a técnica de fonoforese.

Segundo a literatura, o fenômeno físico da onda acústica denominada cavitação seria o principal mecanismo no qual esta técnica se utiliza para aumentar a permeação de princípios ativos, pois induz a desordem na camada córnea, 
com a formação de microbolhas gasosas que ao se romperem violentamente, permitem a passagem do fármaco (Fang et al., 1999), (Ueda et al., 1996), (Miller, 2000). A camada córnea produz alta resistência à penetração de substâncias através da pele, e o US, desorganizando o estrato córneo, pode reduzir em 30\% essa resistência (Mitragotri et al., 1995).

No entanto, em termos de liberação in vitro existem poucos estudos, sabe-se que o ultrassom é capaz de ampliar a absorção espectrofotométrica do ativo em sistema de difusão vertical semelhante (Bianchetti et al., 2009).

Acredita-se que a técnica de fonoforese se utiliza do mesmo princípio físico descrito acima em estudos de permeação para ampliar a liberação da rutina para o meio receptor, uma vez que a onda sonora gera uma perturbação do meio, promovendo um movimento mais rápido das partículas encorajando a absorção das mesmas (Low; Reed, 2001).

Estudos mais recentes relatam que a fonoforese se utiliza além da cavitação, de fenômenos como microstreaming e aquecimento para ser efetiva (Pahade et al., 2010). O microstreaming tem sido descrito como mecanismo responsável pela fonoforese em estudos in vitro (Simonin, 1995), este fenômeno pertence a uma classe de manifestações acústicas relacionadas a movimentos de força, deformações e tensões em escala geométrica pequena, estes se fazem evidentes em uma variedade de circunstâncias, mas especialmente em meios líquidos, com aparelhos ciclados em frequências em gama inferiores e baixos níveis de intensidade ou de pressão e amplitude (Nyborg, 1982).

Investigações mostram ainda que, quando o ultrassom está programado no modo contínuo o efeito térmico pode ser considerado o principal fator para aumentar a permeação percutânea (Machet et al., 1998). No entanto, em termos de liberação in vitro existem poucos estudos, sabe-se apenas que o aumento de temperatura causada pela libertação de calor incrementa a difusividade da droga (Simonin, 1995) e a cinética da mesma.

É possível que o efeito térmico do ultrassom contínuo tenha atuado de forma efetiva sobre a estrutura química do veículo, acentuando a liberação do ativo. Estudos mostram que a velocidade de liberação de uma substância é determinada pela concentração da fórmula, característica do próprio polímero e também por influências extras como, por exemplo, alternância de temperatura (Rojas et al., 2004), uma vez que o ácido carboxivinúlico, quando em contato com temperaturas mais altas, altera seu comportamento reológico (Corrêa et al., 2005).

No gráfico (FIGURA 3) tem-se a comparação de permeação da rutina nos tempos 5, 10, 15 e 20 minutos quando submetidos ao tratamento com onda ultrassônica.

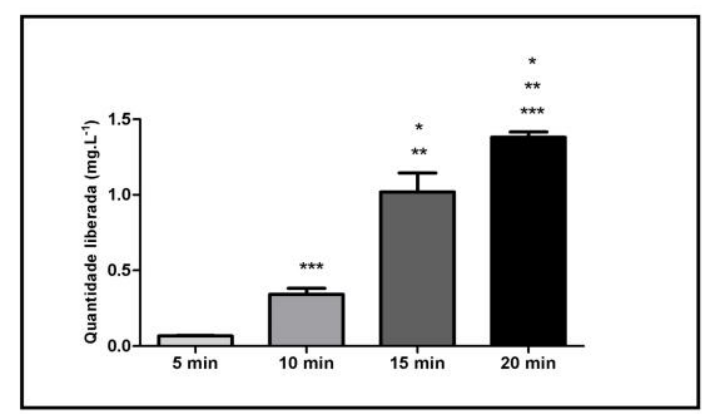

Figura 3: Análise de liberação nos tempos de 5, 10, 15 e 20 minutos como a presença de fonoforese ${ }^{*} \mathrm{p}<0,05$ vs 5 minutos. ${ }^{* *} \mathrm{p}<0,05$ vs 10 minutos. ${ }^{* *} \mathrm{p}<0,05$ vs 15 minutos. Fonte: Dos autores (2014).

Os resultados mostraram que entre 5 e 10 minutos de aplicação da fonoforese não houve diferença estatística em termos de liberação do princípio ativo para o meio receptor, no entanto, quando comparamos os tempos 10, 15 e 20 essa diferença foi significativa. Em termos percentuais, pode-se evidenciar que 15 minutos de aplicação acústica sobre o sistema de difusão aumentou $297 \%$ a liberação do ativo em relação a 10 minutos, já 5 minutos a mais de radiação sônica (tempo de 20 minutos) tiveram a capacidade de incrementar em $136 \%$ a liberação do ativo para o meio receptor, quando comparado com o tempo de 15 minutos.

Os resultados sugerem que quanto maior for o tempo de aplicação da técnica, maior é a liberação da rutina para o meio receptor. Esse resultado está relacionado ao fato de que, tempo de irradiação sonora, incidência de energia e aquecimento estão diretamente relacionadas, (Mitragotri; Kost, 2004), ou seja, quanto maior for o tempo de aplicação da técnica, maior é a incidência de onda sonora sobre o fármaco, a 
temperatura do mesmo e consequentemente a liberação para o meio receptor.

Diversos ensaios in vivo e in vitro têm mostrado a ampla variedade de atividades biológicas dos flavonoides sobre sistemas biológicos, já foram descritas pela literatura: capacidade antioxidativa, anti-inflamatória, vasodilatadora, antialérgica, antihepatotóxica, antiulcerogênica, antiplaquetária, antimicrobianas, antivirais, bem como atividade contra o desenvolvimento de tumores (Oliveira et al., 2004).

Atualmente, estudos in vivo têm comprovado os efeitos benéficos da rutina, principalmente no que diz respeito à sua ação anti-inflamatória. Uma pesquisa utilizando modelo de inflamação aguda e crônica em ratos mostrou que a rutina apresenta melhores resultados quando comparada com outros flavonoides como a quercetina e hesperidina em administração intraperitoneal (Guardia et al., 2001). No entanto, a administração tópica da rutina parece ainda estar distante da prática clínica, devido a sua baixa capacidade de liberação e consequentemente de permeação, Baby e colaboradores (2008), mostraram que a rutina em emulsão apresenta uma boa estabilidade, todavia, a taxa de permeabilidade em modelo de biomembrana se apresentou como não favorável (Baby et al., 2008).

Existe uma quantidade relevante de pesquisas buscando métodos de incrementar a liberação de ativos, inclusive sobre rutina. Recentemente, cientistas mostraram que a presença de propileno glicol 5,0\% se apresentou estatisticamente favorável para promover a liberação de rutina em sistema semi-sólido com fluxo $=105,12 \mu \mathrm{g} / \mathrm{cm}^{2}$.h. Calculamos o fluxo de liberação da rutina sob influência da onda sonora, mesmo que os sistemas sejam semelhantes e não idênticos aos da pesquisa referenciada, podemos evidenciar que $\mathrm{o}$ ultrassom ampliou a liberação do fluxo em $746 \%$, ou seja, o fluxo de liberação da rutina sob influência do ultrassom foi de 785,01 $\mu \mathrm{g} / \mathrm{cm}^{2} . \mathrm{h}$.

\section{Conclusões}

Atualmente, tem-se buscado no campo da reabilitação, condutas terapêuticas eficientes com resultados clínicos rápidos e seguros, neste sentido, administração transdérmica de fármacos têm se mostrado uma estratégia competente e como fase inicial para tal análise identifica-se a capacidade de liberação das substâncias. Nestas condições experimentais, os resultados sugerem uma maior liberação da rutina quando associada à onda sônica terapêutica, ou seja, o US contínuo se apresentou como facilitador no processo de liberação da rutina para o meio, sendo que este fato está diretamente relacionado ao tempo de irradiação sonora. Os resultados mostraram que nos tempos de 15 e 20 minutos a fonoforese ampliou cerca de $26 \%$ e $60 \%$, respectivamente, a liberação de rutina quando comparado com o grupo controle, sendo estes resultados promissores para aplicação clínica da técnica

\section{Referências}

Baby, A. R., Haroutiounian-Filho, C. A., Sarruf, F. D., Tavante-Júnior, C. R., Pinto, C. A. S. O., Zague, V., Arêas, E. P. G., Kaneko, T. M., Velasco, M. V. R. (2008). Estabilidade e estudo de penetração cutânea in vitro da rutina veiculada em uma emulsão cosmética através de um modelo de biomembrana alternativo. Ver. Bras. de Ciênc. Farm. Vol. 44. № 2.

Banga, A. K. (2011) Transdermal and intradermal delivery of therapeutic agents, application of physical technologies. New York: CRC Press.

Bianchetti, P., Tassinary, J. A. F., Cerutti, D. G. U., Barnes, D., Ethur, E. M., Stülp, S. (2009). Avaliação eletroquímica e espectrofotométrica de soluções de rutina submetidas a ultrassom terapêutico. Revista Liberato, 10.139p.

Bruneton, J. (1991). Elementos de fitoquímica y de farmacognosia. Zaragoza: Acribia, 594p.

Carter, S. G., Zhu, Z., Varadi, G., Veves, A., Riviere, J. E. (2013). Vasomodulation influences on the transdermal delivery of ibuprofen. Pharmaceutics, Drug Delivery and Pharmaceutical Technology, [doi 10.1002/jps.23719].

Corrêa, N. M., Camargo Júnior, F. B., Ignácio, R. F., Leonardi, G. R. (2005). Avaliação do comportamento reológico de diferentes géis hidrofílicos. Revista Brasileira de Ciências Farmacêuticas Brazilian Journal of Pharmaceutical Sciences. jan./mar, 41(1). 
Fang, J. Y., Fang, C. L., Sung, K. C., Chen, H. Y. (1999). Effect of low frequency ultrasound on the vitro percutaneous absorption of clobetasol 17propionate. lnt. J. Pharm, 9: 33-42.

Guardia, T., Rotelli, A. E., Juarez, A. O., Pelzer, L. E. (2001). Anti-inflammatory properties of plant flavonoids. Effects of rutin, quercetin and hesperidin on adjuvant arthritis in rat. Elsevier. IL Farmaco, 56, 683-687.

Guirro, E., Guirro, R. (2002). Fisioterapia dermatofuncional: fundamentos, recursos, patologias.3. ed. São Paulo: Manole, 560p.

Harris, M. I. C. N. (2003). Biologia geral. Biologia da pele. Pele: estrutura, propriedades e envelhecimento. São Paulo: Senac.

Kitchen, S., Bazin, S. (1998). Eletroterapia de Clayton. 10. ed. São Paulo: Manole, 350p.

Low, J., Reed, A. (2001). Eletroterapia explicada princípios e prática. 3. ed. São Paulo: Manole, 472p.

Machet, L., Cochelin, N., Patat, F., Arbeille, C., Machet, M. C., Lorette, G., Vaillant, L. (1998). In vitro phonophoresis of mannitol, oestradiol and hydrocortisone across human and hairless mouse skin. International Journal of Pharmaceutics, 165: 169-174.

Miller, M. W. (2000). Gene transfection and drug delivery. Ultrassound in Med. Biol, 26(1): 59-62.

Mitragotri, S., Edwards, D. A., Blanksfchtein, D., Langer, R. (1995). A mechanistic study o f ultrasonically enchanced transdermal delivery. J. Pharm. Sei, 84: 697-706.

Mitragotri, S., Kost, J. (2004). Low-frequency sonophoresis a review. Advanced Drug Delivery Reviews, 56: 589-601.

Mota, A. C. V., Volpato, N. M., Freitas, Z. M. F., Santos, E. P. (2008). Estudo de liberação in vitro do filtro solar p-metoxicinamato de octila incluso em lipossoma e ciclodextrina. Rev. Ciênc. Farm. Básica Apl. set/dez, 29(3):285-289.

Nyborg, W. L. (1982). Ultrasonic Microstreaming and Related Phenomena. Br. J. Cancer, 45(V):156.
Oliveira, T. T., Nagem, T. J., Lopes, R. M., Moraes, G. H. K., Ferreira Junior, D. B., Silva, R. R., Maia, J. R. S. (2004). Efeito de diferentes doses de rutina sobre lipídeos no soro de coelhos machos e fêmeas. RBAC, vol. 36(4): 213-215.

Pahade, A., Jadhav, V. M., Kadam, V. J. (2010). Sonophoresis: An Overview Quality Assurance dept, Bharati Vidyapeeth's College of Pharmacy, CBD Belapur, Navi Mumbai, Maharashtra, India. jul./aug. 3(2), [Article 005].

Prentice, W. E. (2004). Modalidades terapêuticas para fisioterapeutas. 2. ed. Porto Alegre: Artmed, 612p.

Rogero, S. O., Lugão, A. B., Ikeda, T. I., Cruz, A. S. (2003). Teste in vitro de Citotoxicidade: Estudo Comparativo entre Duas Metodologias. Mat. Res. 6,317 .

Rojas, O., Moya, M., Sibaja, M., Ruepert, C., VegaBaudrit, J. (2004). Estudio de la Liberacion Controlada de Plaguicidas Incorporados en Hidrogeles de Acido Itacónico. Revista Iberoamericana de Polímeros. nov. 5(3).

Simonin, J. P. (1995). On the mechanisms of in vitro and vivo phonophoresis. Journal Of Controlled Release, 33:125-141.

Ueda, H., Ogihara, M., Sugjbayashi, K., Morimoto, Y. (1996). Difference in the enhancing effects of ultrasound on the skin permeation of polar and non-polar drugs. Chem. Pharm. Buli, 44(10): 19731976.

Velasco, M. V. R., Balogh, T. S., Pedriali, C. A., Sarruf, F. D., Pinto, C. A. S. O., Kaneko, T. M., Baby, A. R. (2008). Associação da rutina com pmetoxicinamato de octila e benzofenona-3: avaliação in vitro da eficácia fotoprotetora por espectrofotometria de refletância. Lat.Am. J. Pharm. Buenos Aires, 27(1):23-27.

Young, S. R., Dyson, M. (1990). Effect of therapeutic ultrasound on the healing of full thickness excised skin lesions. Ultrassonics, 28: 175-180. 